\title{
EL PAPEL DE LA PRENSA EN LOS CONGRESOS INTERNACIONALES DE LA LENGUA ESPAÑOLA: DESPLAZAMIENTOS EN EL MARCO DE LA POLÍTICA LINGÜÍSTICA PANHISPÁNICA ${ }^{1}$
}

\author{
The role of the press in the International Congresses of the Spanish Language: \\ displacements in the context of the panhispanic language policy
}

María Florencia Rizzo*

\begin{abstract}
RESUMEN
El propósito de este artículo es examinar, desde el enfoque teórico de la Glotopolítica, el papel asignado a la prensa escrita en el marco de la política lingüística panhispánica que ha implementado España en las últimas décadas, a través del análisis de uno de sus dispositivos fundamentales: los Congresos Internacionales de la Lengua Española (CILE). Estos acontecimientos son organizados principalmente por el Instituto Cervantes, la Real Academia Española y la Asociación de Academias de la Lengua Española para reflexionar y debatir la agenda pública del español. El análisis se centra en dos aspectos: 1. el espacio que ocupan los medios de comunicación, en especial la prensa escrita, en los programas de los primeros CILE (1997-2007) y 2. un conjunto de discursos que reflexionan sobre el estado de la lengua en este medio. El estudio muestra la permanencia de una ideología lingüística de orientación purista a lo largo de los congresos; asimismo, se observa un desplazamiento del papel de los medios que participan en estos encuentros, desde un lugar de pugna -en el I CILE de 1997- con las academias de la lengua por las funciones concernientes a cada sector, a uno de complementariedad con la política panhispánica.
\end{abstract}

Palabras clave: política lingüística panhispánica, prensa escrita, ideología lingüística, Congresos Internacionales de la Lengua Española, academias de la lengua.

\begin{abstract}
The purpose of this article is to examine, from Glottopolitics' theoretical framework, the role assigned to the written media in the context of the panhispanic language policy that Spain has implemented in recent decades, through the analysis of one of its devices: the International Congresses of the Spanish Language (CILE). These events are organized by the Cervantes Institute, the Royal Spanish Academy and the Association of Academies of the Spanish Language to reflect and discuss the public agenda of Spanish. The analysis centres on two aspects: 1. the space that the mass media occupies, especially that of the press in the programs of the first CILE (1997-2007) and 2. a set of speeches that reflect on the use of language in this medium. The study shows the permanence of a purist linguistic ideology throughout the congresses. In addition, a displacement of the role of the media that takes part in these meetings is observed from a place of struggle -in the I CILE of 1997- with the academies of the language for the functions relating to every sector, to one that complements the panhispanic language policy.
\end{abstract}

Key Words: panhispanic language policy, written media, language ideology, International Congresses of the Spanish Language, academies of language.

* Universidad de Buenos Aires (UBA). Investigadora asistente del Consejo Nacional de Investigaciones

Científicas y Técnicas (CONICET).Correo electrónico: rizzoflorencia@gmail.com

Recepción: 13/1/17. Aceptación: 24/5/17. 


\section{Introducción}

Con el avance de los procesos de globalización, en las últimas décadas se han acentuado algunos de sus aspectos, entre los que se destacan el crecimiento del comercio mundial, la multiplicación de organismos internacionales, el desarrollo tecnológico, los procesos migratorios, la expansión de los medios de comunicación y la internacionalización de los adelantos científicos, los cuales han despertado el interés por el tema de las lenguas mundiales $\mathrm{y}$, en especial, de la lengua que ocupa, sin duda alguna, la posición preeminente: el inglés. Frente a esta situación, otras lenguas mayores, como el español, el francés y el portugués, buscaron aumentar su presencia mundial en ámbitos donde fuera posible competir o complementarse con el idioma hegemónico, mediante el desarrollo de políticas de áreas idiomáticas -tendientes a su consolidación como lenguas internacionales- las cuales plantean una supuesta gestión democrática de la lengua compartida y se interesan por favorecer alianzas políticas así como por estimular los negocios de los países que lideran el emprendimiento, esto es, aquellos que cuentan con mayor peso político y económico (Arnoux, 2013).

En el caso del español, es el gobierno peninsular el que a través de la RAE y del Instituto Cervantes, junto con el apoyo de otros actores sociales, ha desplegado desde fines del siglo XX y principios del XXI una política lingüística designada como panhispánica. ${ }^{2}$ En los últimos años se han realizado numerosos estudios que indagan la dimensión ideológica de esta política (entre los más recientes, Fanjul, 2011; Moreno Cabrera, 2011: 254-296; Lara, 2011; Senz, 2011: 224-274; Paffey, 2012; Del Valle y Villa, 2012; Subirats Rüggeberg, 2014; Del Valle, 2014; Arnoux, 2013; 2015a y 2015b) así como sus agentes y dispositivos de desarrollo y difusión, entre los cuales se ha considerado la prensa (Paffey, 2007; Marimón Llorca, 2015) 3 y los Congresos Internacionales de la Lengua Española (CILE) (Arnoux, 2008; Rizzo, 2013 y 2014; Marimón Llorca, 2015). Estos encuentros, convocados por las dos instituciones españolas ya mencionadas junto con la Asociación de Academias de la Lengua Española (ASALE) para reflexionar y debatir las cuestiones que están o deben estar en la agenda pública del español, constituyen un espacio de gestación de dicha política y de visibilización de la orientación político-lingüística que se busca instalar y difundir dentro y fuera del mundo hispánico (Rizzo, 2014). Se trata de acontecimientos discursivos que expresan la voluntad de construir, por un lado, una lengua homogénea que pueda desempeñarse en diversos ámbitos como lengua internacional $\mathrm{y}$, por el otro, de mostrar una comunidad de pertenencia donde se gestiona democráticamente la "lengua común". Como parte de este proceso entran en juego negociaciones con diversos agentes, entre ellos los medios de comunicación, en especial la prensa escrita, que incluyen, por ejemplo, el "grado" de participación en la elaboración de instrumentos lingüísticos que se presentan como comunes en toda el área hispánica. De ahí que el propósito de este trabajo sea examinar el espacio que ocupa la prensa escrita en estos encuentros y la ideología lingüística que recorre los discursos sobre el uso del español en este medio.

\section{Marco teórico y corpus de análisis}

El estudio se inscribe en el enfoque glotopolítico (Arnoux, 2000; Arnoux y Del Valle 2010; Arnoux, 2014) que propone, a partir del análisis discursivo de diversos materiales de archivo, la indagación de distintas formas de intervención en el espacio público del lenguaje y examina las ideologías lingüísticas que impulsan, considerando su relación con los procesos sociohistóricos en los que participan. Estas acciones pueden emerger tanto de espacios estatales como desde agentes no gubernamentales que tienen repercusión pública sobre las lenguas y las prácticas discursivas, a partir de la consideración de los múltiples discursos sociales donde se reconocen dichas intervenciones, atendiendo a distintos recortes temporales (desde la focalización en la coyuntura de determinados procesos hasta la indagación de 
períodos de mediana o larga duración). Estos materiales se constituyen en objetos de estudio, por ejemplo, por su difusión pública, por su participación o por su incidencia en instancias donde se toman decisiones que afectan el espacio del lenguaje (Arnoux, 2014). En nuestro caso, la propuesta de análisis de los CILE adquiere relevancia en tanto se trata de espacios con una considerable repercusión pública cuyos discursos legitiman, cuestionan o naturalizan determinadas representaciones de lengua y propuestas de intervención en el español.

Dado que este trabajo se enmarca en una investigación mayor sobre los antecedentes e inicios de la política lingüística panhispánica, nos interesa indagar los primeros congresos realizados: el I CILE "La lengua española y los medios de comunicación" (Zacatecas, 1997), el II CILE "El español en la sociedad de información" (Valladolid, 2001), el III CILE "Identidad lingüística y globalización" (Rosario, 2004) y el IV CILE "Presente y futuro de la lengua española: unidad en la diversidad" (Cartagena de Indias, 2007). El corpus de análisis está conformado, por un lado, por los programas de temas porque este espacio forma parte de la dimensión programática de los encuentros (Rizzo, 2013), es decir, la instancia donde se presentan los lineamientos que guían el acontecimiento, los temas elegidos así como los excluidos; por otro lado, analizaremos una selección de exposiciones que reflexionan sobre el estado de la lengua en la prensa escrita a cargo de periodistas, autoridades de diarios y profesores universitarios.

Siguiendo lo anterior, el recorrido del artículo propone dos instancias de análisis. En los programas de los CILE indagaremos el lugar que ocupan los medios $\mathrm{y}$, en particular, el periodismo escrito. El objetivo es observar, a grandes rasgos, el grado y el modo de participación de estos sectores a lo largo de los años a partir del examen de los títulos de las diferentes secciones en que se dividen los congresos y del tipo de expositores convocados; así, buscamos identificar cuáles son las voces autorizadas para reflexionar sobre los medios de comunicación, principalmente, sobre prensa escrita, qué sectores de los programas están destinados a tratar estos asuntos y cuáles son las problemáticas que se destacan.

A continuación, examinaremos los discursos seleccionados de acuerdo con tres ejes: el papel que los diferentes actores cumplen en la regulación de la norma, la cuestión del cambio lingüístico, en particular, de la influencia de extranjerismos, y la relación entre norma y uso. El análisis busca explicar cómo se concibe el papel de los medios en relación con el uso del español y determinar si permanece la tensión entre los sectores del periodismo y de la academia que se identifica en el I CILE de 1997 (Rizzo, 2013), tema que explicaremos en el siguiente apartado, o si las posiciones de ambos agentes tienden a converger en algún momento y por qué.

\section{Medios de comunicación y prensa escrita en los programas de los congresos}

El desarrollo de la globalización instaló la consideración de las áreas lingüísticas pero también generó posiciones de defensa idiomática, lo que trajo aparejada, entre otras cuestiones, la preocupación por la incidencia de los medios de comunicación en la lengua. En el ámbito hispánico, el tratamiento de esta cuestión cobró especial relevancia en la década de 1980 a partir de la realización de eventos como el Encuentro "Salamanca 80", donde se reunieron académicos, lingüistas e intelectuales hispanohablantes para analizar el futuro de la lengua española en relación con los medios; la Primera Reunión de Academias de la Lengua Española sobre el Lenguaje y los Medios de Comunicación (Madrid, 1985); o el Seminario Internacional "El idioma español en las agencias de prensa" (Madrid, 1989), organizado principalmente por la Agencia EFE, en el que participaron representantes de agencias internacionales de información que tienen servicio en español, miembros de agencias nacionales de información hispanoamericanas, 
editores de diarios internacionales, académicos, filólogos y periodistas.

Como ya comentamos, las transformaciones asociadas con los procesos de globalización económica que tuvieron lugar en las dos últimas décadas del siglo XX -los cuales conllevan, a su vez, modificaciones en las funciones de los Estados nacionales donde se evidencia el creciente borramiento de los límites entre el ámbito público y privadoincidieron en el espacio de las lenguas y dieron lugar a la multiplicación de las instancias reguladoras. En este marco, el desarrollo y crecimiento de la circulación de medios masivos de comunicación acentuó la preocupación por la influencia que estos ejercen en las lenguas. En el ámbito hispánico aumentaron su presencia con la publicación de dispositivos normativos como son los manuales de estilo periodístico desde fines de la década de 1970, en España y en algunos países latinoamericanos como México, Colombia, Venezuela y Argentina (Arnoux, Blanco y Di Stefano, 1999). Este tipo de acciones de intervención en la lengua -que se acentuó en las décadas de 1980 y de 1990-ubicó a los medios en una posición privilegiada que antes ocupaban casi enteramente las academias: asumieron una función social importante como agentes de intervención glotopolítica y, hasta, específicamente, como agentes educadores. Así se asistió a la emergencia de un nuevo agente que puso de relieve el desplazamiento de las funciones del Estado por la primacía de los intereses económicos (Arnoux, Blanco y Di Stefano, 1999: 181) que buscan un mercado unificado más rentable, en un territorio que trascienda los límites nacionales. Sin embargo, dado que se trata de papeles dinámicos, con el correr de los años los medios de comunicación fueron sufriendo transformaciones de acuerdo con cambios glotopolíticos y tecnológicos (cf. Arnoux, 2015a). En este marco, nos interesa indagar en los CILE algunos desplazamientos en lo que concierne a su incidencia en la regulación del lenguaje.

En efecto, a lo largo de los encuentros se fue modificando el espacio concedido a los medios de comunicación $y$, en particular, a la prensa escrita. El I CILE (Zacatecas, 1997) se destacó sobre los demás debido a que es el único que aborda el tema de forma exclusiva. El desarrollo de esta cuestión se despliega en las seis secciones que integran el encuentro: El libro, La radio, La televisión, El cine, Las nuevas tecnologías y La prensa. En relación con el último eje, cabe destacar que este primer congreso internacional fue escenario de la presentación del proyecto Zacatecas que consistía en la elaboración de un libro de estilo unificado por parte de los principales diarios en español para todo el ámbito hispanohablante. ${ }^{4}$ Además allí tuvieron lugar tres mesas redondas sobre la cuestión: "La lengua española en la formación del periodista", "Los medios de comunicación y el futuro de la lengua española" y "Las academias de la lengua y los medios de comunicación".

En Rizzo (2013), a partir del análisis de esta última sección, observamos que el Congreso de Zacatecas expone un momento donde los medios de comunicación, en especial la prensa escrita, adquieren legitimidad mientras que las academias sufren cierto desplazamiento. Para comenzar, la propuesta de inclusión en el programa de una mesa temática con aquel título es significativa en sí misma: exhibe la necesidad de diálogo entre ambos agentes. A la vez, muestra que los medios de comunicación son identificados como interlocutores que se encuentran en pie de igualdad respecto de las academias ya sea para criticar, reclamar o delimitar las funciones que corresponden a cada sector. En este sentido, en los discursos surgieron reclamos explícitos hacia las academias por la falta de contacto que tienen con la sociedad, lo cual deriva en una inadecuación de su trabajo a la realidad, al uso, es decir, en una falta de acompañamiento de los cambios que transita la lengua. Si bien desde el discurso de los medios no se cuestiona la autoridad lingüística de las academias, se insinúa cierto "autoritarismo" en la medida en que se remarca que la lengua es de todos y que las academias no son dueñas del idioma. En cuanto a la función que cumplen los medios de comunicación, estos reivindican su papel como agentes reguladores del lenguaje, 
principalmente en lo que respecta a la detección del cambio lingüístico, y de difusión idiomática en el mundo hispanohablante.

En suma, el Congreso de 1997 revela un momento de tensión entre las academias y los medios de comunicación donde estos expresan una demanda de renovación de aquellas y reclaman, en consecuencia, una relación de complementariedad entre ambos agentes, lo cual supone una dependencia mutua y un trabajo conjunto.

En los acontecimientos que suceden al de Zacatecas los medios de comunicación ya no tienen tal protagonismo, aunque permanecen como tema estable en los programas, lo cual da cuenta de la importancia que tiene este sector en la agenda glotopolítica del español. El II CILE (Valladolid, 2001) le destina un espacio considerable dentro del eje temático $E l$ español en la sociedad de información, donde se organizaron diferentes paneles: "La radio en español", "La televisión en español", "Internet en español", "El cine en español" y "La prensa en español". A su vez, esta última comisión se dividió en "Prensa en español y cultura iberoamericana" y "La prensa hispánica en la sociedad de información".

En el caso del III CILE (Rosario, 2004) la temática se desarrolló dentro de la sección Español internacional e internacionalización del español. En este encuentro el asunto pierde centralidad ya que los distintos tipos de medios no son abordados de modo específico sino que son tratados en tres paneles generales: "El español estándar y sus variedades en los medios de comunicación", "Medios de comunicación y creación de cultura iberoamericana (I)" y "Medios de comunicación y creación de cultura iberoamericana (II)".

Por último, en el IV CILE (Cartagena de Indias, 2007) detectamos un movimiento inverso al del congreso anterior: ya no se tratan los medios de comunicación globalmente sino que se circunscribe el tema a la prensa escrita dedicada a asuntos culturales y se concede un único panel para desplegarlo: "El periodismo cultural iberoamericano". Como elementos en común, identificamos dos lexemas que ya estaban presentes en el Congreso de 2004: cultural e iberoamericano.

De acuerdo con esta somera descripción podemos arribar a algunas conclusiones provisorias. A grandes rasgos, observamos que a lo largo de los CILE la cuestión de los medios de comunicación pasa de ser un asunto prioritario de debate a ocupar un espacio más periférico, aunque no por ello ausente. Entendemos que la disminución del interés en el tema da cuenta de un cambio en el modo de concebir el papel de los medios en relación con el uso del español: estos dejan de ser el foco de atención, en el sentido de constituirse en centro de críticas, como ocurre en el I CILE de 1997 (cf. Rizzo, 2013) y pasan a ocupar la posición de "aliados" o de agentes que "acompañan" la orientación de la política panhispánica encarada por la RAE. ${ }^{5}$ Como señalamos anteriormente, el momento de mayor tensión se produce en el Congreso de Zacatecas, donde se desenvuelve un debate entre las academias y los medios que expresa una "lucha de poder" entre ambos sectores, mientras que en los encuentros siguientes, los medios dejan de estar en la mira pero cuentan con un espacio de reflexión (Rizzo, 2013). En esta dirección, creemos que la inclusión de la cuestión de los medios de comunicación en el eje Español internacional e internacionalización del español en el Congreso de Rosario, junto con mesas sobre la enseñanza del español a extranjeros y la certificación de competencias, supone la integración de dichos medios y de los actores involucrados en ellos, tanto periodistas como empresarios, en la política de internacionalización del español que han impulsado la RAE y el Instituto Cervantes. ${ }^{6}$ Este movimiento que estamos señalando tiene una correspondencia en el plano discursivo que analizaremos en el apartado siguiente.

Por otra parte, a partir del Congreso de Valladolid, los términos prensa, medios de comunicación y periodismo son vinculados al lexema cultura o cultural. Vislumbramos que esta asociación remite al supuesto de que la prensa dedicada a temas culturales es el sector que "cuida", en mayor medida, el lenguaje. 
En lo que respecta a los actores que participan en las sesiones plenarias, paneles y mesas redondas antes mencionadas, identificamos, en términos generales, tres tipos de agentes: periodistas y directivos de diarios, de grupos empresariales y de agencias de prensa; profesores y autoridades de universidades latinoamericanas y -mayormente- españolas; representantes de la RAE y de otras academias hispánicas. ${ }^{7}$

En efecto, observamos la participación de determinadas figuras o sectores representados que se reiteran: integrantes de las academias, sobre todo de España y, en menor medida, de Colombia y de México; miembros de la agencia de noticias EFE, principalmente Álex Grijelmo y Alberto Gómez Font; también es frecuente la asistencia de algunos diarios del ámbito hispánico de gran alcance, no solo nacional sino también internacional, como El pais, $A B C, E l$ mundo y La vanguardia ${ }^{8}$ de España, Clarín de la Argentina, El tiempo de Colombia y Ecuador. ${ }^{9}$ Por último, en lo que concierne a los medios de habla hispana en los Estados Unidos, se destaca la participación de Radio Caracol de Miami.

Muchas de las instituciones y empresas a las que pertenecen estos agentes -con predominio peninsular- se encuentran vinculadas entre sí y cuentan con influencia en numerosos países latinoamericanos mediante la firma de diversos acuerdos comerciales. Sin pretensión de exhaustividad, mencionamos a continuación algunas de las conexiones que se han dado en los últimos años. La Agencia EFE, la primera y más grande agencia de noticias en español, ${ }^{10}$ patrocina, junto con el BBVA, la Fundéu, que cuenta con el asesoramiento de la RAE y ha incluido personalidades como Víctor García de la Concha, Humberto López Morales y Gregorio Salvador en el Consejo Asesor y como José Manuel Blecua y Luis María Anson en el Patronato. La entidad mantiene acuerdos con la Corporación madrileña, el Instituto Cervantes, ${ }^{11}$ la Academia Argentina de Letras $^{12}$, el canal de televisión CNN en español, el periódico El Tiempo de Bogotá y La Vanguardia de Barcelona, entre otros. ${ }^{13}$ Por su parte, tanto el diario El país como Radio Caracol $^{14}$ de Miami pertenecen al Grupo empresarial español Prisa. Por último, cabe mencionar que entre el 2007 y el 2012 el Grupo multimedio español Planeta, que también ha establecido convenios editoriales con la RAE para la publicación de las obras académicas, ${ }^{15}$ fue el principal accionista del diario colombiano El tiempo. ${ }^{16}$ De este modo, se identifica una red de medios e instituciones vinculadas a fuertes grupos económicos de capital español que presenta regularidad en los CILE; muchas de ellas, a su vez, mantienen relaciones con los agentes que han impulsado la política lingüística panhispánica.

\section{EI uso de la lengua en la prensa escrita}

Teniendo en consideración lo analizado hasta el momento, en esta parte del trabajo nos interesa relevar qué posiciones acerca de la lengua se identifican en los discursos sobre la prensa en los CILE; en relación con el panorama del Congreso de 1997, buscamos responder si permanece o cede la tensión entre los medios y las academias comentada en el apartado anterior.

En cuanto a la primera pregunta planteada, observemos en los siguientes fragmentos la insistencia en la cuestión de la defensa idiomática:

a. A través de los multimedios convivimos, queramos o no, con la avalancha de extranjerismos: los encontramos tercamente en las etiquetas o letreros de los productos que consumimos, en los establecimientos y edificios de nuestras ciudades. Aunque, debido a nuestra escasa contribución a la tecnología actual, no estemos en disposición de crear nuevo léxico, no podemos bajar la guardia y estar a lo que nos den o venga dado del exterior. Es un hecho, además, que en los medios de comunicación el flujo de voces extrañas es caudaloso. En los libros y en la prensa escrita abundan las palabras en letras cursivas, recurso tipográfico para señalar que tales elementos o expresiones son huéspedes o forasteros en nuestra lengua.

Soy de la opinión de que, en estos males del lenguaje, como es lógico, tiene la última 
decisión un posible a modo de «Laboratorio léxico» en/de la Real Academia Española (Mourelle de Lema, 1997). ${ }^{17}$

b. Una de las oportunidades de hacer una labor común en defensa del español es la de defenderse de los ataques de otras lenguas, las que se han llamado invasoras, por su afán de ganar el terreno a la nuestra desde la proximidad geográfica o de la superioridad política y económica. Me refiero, como es fácil de suponer, a la manera de contrarrestar la injerencia de vocablos foráneos, no cuando vienen a cubrir el vacío que pueda haber en nuestro idioma, originado por los avances técnicos o los cambios de usos y costumbres que se deriven de ellos o son fruto de las nuevas corrientes sociales (Fernández Pombo, 2001).

c. Y si digo que me congratulo especialmente de estar hoy sentado aquí es porque, justamente, la defensa de la pureza del idioma ha sido desde siempre una de las preocupaciones centrales de La Nación, el diario de Buenos Aires cuya dirección ejerzo desde hace quince años. (...)

La tercera responsabilidad sobre la cual considero necesario insistir es la que tiene que ver con esa misión irrenunciable de los medios periodísticos de velar el buen uso del castellano, por evitar la degradación del idioma que nos confiere identidad (Mitre, 2001).

d. Algunas personas han sido arrastradas a adoptar valores y modos de expresión de sociedades como la estadounidense (...).

En este punto, cabrían, entonces, otras preguntas: ¿hasta dónde y porqué hemos permitido que esto pase? ¿Hemos sido lo suficientemente diligentes y atentos para enfrentar las amenazas globalizadoras que se ciernen sobre nuestra cultura? ¿Qué estamos haciendo y qué haremos por reforzar y crear cultura iberoamericana?

En el periódico El Tiempo de Bogotá, conscientes de estas realidades, no nos hemos quedado cruzados de brazos. En 1997 creamos una Defensoría del Lenguaje y elaboramos un Manual de Redacción; desde hace nueve años venimos organizando y realizando anualmente un concurso nacional de ortografía (...) (Santos Calderón, 2004). e. Nos importa mucho nuestra lengua y estamos dispuestos a venerar a quienes nos la cuiden. De hecho, yo me dediqué a escribir sobre esto porque se me ocurrió que tal vez así me venerara alguien. Yo venero a todos los articulistas que he citado; también a los que se me olvidan. $Y$ a todos ellos hay que sumar ahora las recomendaciones de la Fundéu (la Fundación del Español Urgente, creada por la agencia Efe y el BBVA) que se publican ya como artículos en muchos diarios de España y de América.

Como he dicho otras veces, nuestra cultura no es inferior a ninguna; no tenemos por qué llenarnos de anglicismos que refuerzan ese sentimiento de inferioridad al que somos tan propensos; sentirse superior a otro no le hace a uno superior. Pero en el momento en que alguien se siente inferior a otro, empieza a ser realmente inferior (Grijelmo, 2007).

En estas citas identificamos expresiones que dan cuenta de posiciones de defensa lingüística: "no podemos bajar la guardia", "una labor común en defensa del español", "la defensa de la pureza del idioma", "velar [por] el buen uso del castellano", "evitar la degradación del idioma", la creación de una "Defensoría del Lenguaje". Algunos términos contienen un sentido presupuesto que produce un efecto de evidencia, es decir, que la información se presenta como preexistente: así, por ejemplo, toda "defensa" supone algún tipo de ataque, la existencia de alguien o algo del cual defenderse; las nominalizaciones como "pureza" y "degradación" también exhiben un sentido presupuesto, se construyen como objetos conocidos e incuestionables. En todos los casos que estamos analizando, el inglés es concebido como la lengua que amenaza la integridad del español; aluden a él expresiones como las siguientes: "avalancha", "voces extrañas", "defenderse de los ataques de otras lenguas", "invasoras", "enfrentar las amenazas globalizadoras", "no tenemos por qué llenarnos de anglicismos". El Congreso de Zacatecas es el acontecimiento donde es preeminente esta orientación; sin embargo, como se puede observar en los fragmentos citados, este discurso permanece en las exposiciones sobre los medios 
y la prensa a lo largo de los CILE, aunque no cuente con una presencia tan fuerte.

De lo anterior se desprende que las representaciones sobre el lenguaje que circulan en los textos sobre prensa se corresponden con una ideología lingüística ${ }^{18}$ de orientación purista $^{19}$ que considera que los parámetros que se utilizan para evaluar el estado de la lengua son los de corrección e incorrección, que solo los primeros son válidos y que todo lo que se aparta de la normativa debe ser sancionado (Milroy y Milroy, 1985). Desde esta perspectiva, todo factor que afecte un supuesto estado de unidad y pureza de la lengua es connotado negativamente a partir de términos como deterioro, corrupción, ataque, amenaza, fragmentación (cf. Blanco, 1993).

En cuanto a la relación entre quienes trabajan en medios de comunicación y la función de las academias, se produce una modificación significativa respecto del I CILE. La tensión percibida entre ambos agentes cede y da paso a un vínculo de apoyo o complementariedad:

f. Creo sinceramente que sin los libros de estilo de los periódicos nuestro idioma sería ahora algo peor. Y también, que si los periodistas y los académicos nos proponemos trabajar en común podremos todavía resolver muchos más problemas. Todo ello, sin que nadie pierda su personalidad, empezando por la de cada periodista.

Ojalá aceptemos de buen grado ese Diccionario panhispánico de dudas en el que están colaborando expertos y periodistas de las dos orillas del Atlántico (Ceberio Galardi, 2001).

g. En el ámbito lingüístico, la Agencia EFE ha asumido como un compromiso preferente de su misión empresarial la defensa de la unidad del español a ambos lados del Atlántico. Con el propósito de facilitar esta labor, creó en diciembre de 1980 el Departamento de Español Urgente (DEU) (...)

$\mathrm{Su}$ objetivo quedó claramente definido desde su fundación: proporcionar criterios uniformes del uso del español, a fin de evitar la dispersión lingüistica y hacer frente a la invasión indiscriminada de neologismos. En estos veinte años, el Departamento de Español
Urgente, que en verdad funciona como una Unidad de Intervención Rápida ante cualquier agresión al idioma, no ha dejado de dar respuestas a las demandas que se le plantean cada día, por teléfono, por fax, por correo electrónico o por carta (González Reigosa, 2001).

h. Otra razón más para destacar la tarea que tenemos en Estados Unidos los comunicadores para impedir que el español sea reducido en este país a la lengua fraccionada $e$ incoherente que se vislumbra en el futuro cercano. Las alertas rojas son visibles. El avance del spanglish, y el respaldo que recibe de la Universidad de Texas en Austin y de comentaristas hispanos de la televisión, y escritores de prensa, motiva exámenes cuidadosos y profundos sobre estrategias, y con todos los recursos del español disponer lo necesario para contener esta arremetida cultural.

La existencia de la Academia Norteamericana de la Lengua y del Instituto Cervantes en Estados Unidos animan a quienes tratamos de contener la influencia del idioma inglés en el nuestro (Restrepo, 2004).

i. $\quad$ Precisamente para minimizar el uso incorrecto de vocablos y dirimir dudas, además de nuestro propio Manual de estilo y referencia, podemos consultar cuantas veces sea necesario el Diccionario de la Real Academia Española y el Diccionario Panhispánico de Dudas, ambos en línea y con sus constantes actualizaciones. Un instrumento adicional con el que contamos son los boletines que difunde la Fundación del Español Urgente con sus observaciones sobre los vocablos y expresiones que se usan mal en la prensa con más frecuencia, y que nosotros difundimos entre nuestros periodistas para beneficiarnos todos con esos apuntes sobre uso correcto.

Volviendo a nuestro tema, bajo la avalancha de vocablos, expresiones y giros idiomáticos nuevos, se encuentra el español básico, universal, muchas veces en busca de no perder, o para mantener, su brillo y esplendor, como instrumento de comunicación global (Durand, 2007).

En todos los casos, incluso en otras citas mencionadas en este apartado, se marca la necesidad de acudir a textos normativos o a las 
instituciones que los producen para conservar un uso correcto del español: a las academias de la lengua y a los diccionarios que ellas elaboran, al Departamento del Español Urgente de la Agencia EFE que trabaja con el asesoramiento de la RAE, a los manuales de estilo preparados por grandes periódicos. De ahí, entonces, que ya no se conciba la prensa como un espacio de deterioro del español -aunque ello no excluye la presencia de críticas aisladas- sino como ámbito de circulación mundial que permite la amplia difusión de una lengua unificada. En este sentido, las preocupaciones se orientan hacia la dispersión de variedades de español, con lo cual los intereses van a dirigirse a la "construcción" de un español internacional:

j. Los contactos, los intercambios, los préstamos y las interferencias entre unos modelos y otros, al dirigirse todos a un único y potencial lector - el hablante de español_ consolidará esa tendencia que hoy se anuncia, gracias a la encomiable labor desarrollada por las Academias de la Lengua, como es la creación de un espacio común, de un español de uso común, de una mayor familiaridad entre las diversas geografías de la lengua española (Zarzalejos, 2001).

k. Y también aquí, en Rosario, yo propongo que arranque un nuevo proyecto, y les invito a todos a sumarse a él: trabajemos juntos, todos los responsables de los libros de estilo de los medios de comunicación hispanohablantes, colaboremos con la Asociación de Academias de la Lengua Española y con el Instituto Cervantes, con los organismos y las instituciones que se dedican al estudio del español, y con los investigadores sobre el léxico propio de la norma culta en las distintas capitales hispanas; trabajemos todos juntos, como pares, y guiemos el proceso de nacimiento y de crecimiento de ese español internacional (Gómez Font, 2004).

Así, en términos generales, observamos un desplazamiento significativo en los discursos de la prensa respecto del I CILE: del protagonismo de los medios de comunicación como agentes reguladores del lenguaje y del enfrentamiento entre periodistas y académicos por hacer valer las instancias normativas que cada sector produce y por delimitar sus campos de acción se pasa al discurso de la prensa que acompaña el de la política panhispánica; al mismo tiempo, la RAE realiza algunos gestos que actúan en favor de la legitimación del uso de la lengua que hace la prensa. ${ }^{20}$ En esta dirección, la publicación del Diccionario Panhispánico de Dudas $(D P D)$ que ha derivado, de algún modo, de la propuesta de unificación de los libros de estilo periodísticos (Senz, 2011: 247), ha sido un gesto simbólico significativo. Las siguientes palabras sobre el proceso de elaboración de esta obra comentado en el documento de la Nueva Política Lingüistica Panhispánica sintetizan el desplazamiento analizado:

1. Es voluntad de estas [todas las Academias de la Lengua Española] asociar al proceso de elaboración de la obra, mediante consultas, a los grandes medios de comunicación del mundo hispanohablante, que han ofrecido ya su colaboración y el propósito de incorporar a sus respectivos libros de estilo los acuerdos adoptados. Con ello se cumple, además, el propósito fundamental que corresponde hoy a las Academias de la Lengua Española, que no es otro que preservar la unidad del idioma (RAE y ASALE, 2004: 9).

A su vez, unas líneas más adelante se señala que para la selección de las entradas del $D P D$ se tomaron como fuentes, entre otras, las cuestiones tratadas en los libros de estilo de grandes medios de comunicación.

\section{Reflexiones finales}

En este trabajo hemos constatado la presencia que tiene a lo largo de los CILE la ideología lingüística de orientación purista, en particular, en las exposiciones que tratan sobre el uso del español en la prensa escrita. Esta orientación -que se inscribe en la tradición de la queja (cf. Milroy y Milroy, 1985)- se sustenta en una concepción monoglósica de la lengua (cf. Del Valle, 2004). A nuestro entender, esta posición glotopolítica permanece como núcleo estable durante los congresos -si bien va perdiendo intensidad hacia el último encuentroporque integra la matriz hispanista ${ }^{21}$ que 
recorre los CILE (Rizzo, 2016). Este conjunto de regularidades ideológico-discursivas no es exclusivo de estos acontecimientos sino que circula en variadas materialidades discursivas (como instrumentos lingüísticos, ensayos, manuales, periódicos) desde fines del siglo XIX y perdura en la actualidad, aunque con desplazamientos motivados por los cambios coyunturales.

Los actores provenientes de los medios de comunicación $y$, en menor medida, de la universidad que tienen a cargo las exposiciones sobre prensa escrita y que se identifican con la perspectiva antes presentada asumen, en términos generales, el papel de guardianes de la lengua (Milroy y Milroy, 1985) en tanto consideran como tarea necesaria el fomento del uso correcto del idioma y su defensa ante posibles amenazas, en muchos casos desde los diversos espacios que ocupan en los medios de comunicación, con el apoyo de los instrumentos elaborados por la RAE quien, de este modo, legitima su tarea de intervención lingüística.

Finalmente, el análisis de los programas de temas de los CILE y de los discursos sobre la prensa permitió dar cuenta de un desplazamiento del papel de los medios que participan en estos encuentros desde un lugar de pugna con las academias por las funciones concernientes a cada sector (Rizzo, 2013), a uno de alineamiento con la política panhispánica, una suerte de alianza con el poder hegemónico estandarizador cuyo centro visible es la RAE.

\section{Notas}

1. Este trabajo retoma algunas reflexiones presentadas en el VI Congreso Internacional de Letras (Buenos Aires, 25 al 29 de noviembre de 2014).

2. Durante la realización del III Congreso Internacional de la Lengua Española (Rosario, 2004), la RAE y la ASALE dieron a conocer un documento que exponía las bases de una nueva política lingüística que renovaría sus prácticas regulatorias: el reconocimiento de la variedad en el español, de la diversidad al interior de la lengua, compatible con el mantenimiento de la supuesta "unidad básica" del sistema; y el trabajo compartido, en pie de igualdad, entre la RAE y las restantes academias, destinado principalmente a la renovación de los instrumentos lingüísticos.

3. Marimón Llorca analiza el papel de los medios de comunicación, en particular, de la prensa, como aliados de los intereses institucionales y económicos que persigue el panhispanismo. En relación con el lugar que ocupan en los CILE, entiende su presencia "como una estrategia que tiene como objetivo generar un discurso de legitimación -un imaginario social justificador (Pintos, 2005: 11-13), un discurso dominante (Raiter y Zullo, 2008)- que naturaliza una determinada visión de la lengua española: panhispánica, unida en su diversidad, global y capaz, por tanto, de ser generadora de prestigio y riqueza en el mercado mundial" (2015: 126).

4. De acuerdo con S. Senz (2011: 247), quien a su vez cita palabras de Alberto Gómez Font, el proyecto Zacatecas, que aquel había ideado junto con Álex Grijelmo y que iba a tener el patrocinio del Instituto Cervantes, operó como antecedente del Diccionario Panhispánico de Dudas (DPD).

5. Una prueba de ello queda registrada en los agradecimientos del $D P D$, donde se enumeran los medios que colaboraron y apoyaron las decisiones adoptadas en el nuevo texto: "Los días 8 y 9 de octubre de 2004 se celebraron, en la sede de la Real Academia Española, dos sesiones de trabajo con los medios de comunicación para debatir las líneas fundamentales del $D P D$, en particular el tratamiento de extranjerismos y de topónimos.

La Real Academia Española y la Asociación de Academias de la Lengua Española desean dejar constancia de agradecimiento por su colaboración a los siguientes grupos y medios de comunicación Diario Clarín y La Nación (República Argentina), El Mercurio (Chile), El Tiempo (Colombia); La Nación (Costa Rica); El Tiempo (Ecuador), Agencia EFE, Grupo Prensa Ibérica, Grupo Prisa, Grupo Unidad Editorial, Grupo Zeta, Heraldo de Aragón, La Razón, La Vanguardia, La Voz de Galicia y Vocento (España), La Opinión y Nuevo HeraU (Estados Unidos); Grupo Prensa Libre (Guatemala); El Universal y Grupo Reforma (México), El Comercio (Perú), El Nuevo Día (Puerto Rico), Grupo Corripio (República Dominicana), y El Universal (Venezuela)" (RAE y ASALE, 2005: 3).

6. En los últimos años el panorama ha cambiado nuevamente. La importancia que ha ido adquiriendo 
Internet en la difusión de los medios escritos, que pueden ser leídos en áreas amplias y que deben atraer a un gran número de lectores, ha generado la necesidad por parte de estos agentes de intervenir nuevamente en la regulación del lenguaje y de la práctica periodísticos mediante la elaboración de dispositivos normativos propios que atiendan al desarrollo del lenguaje en Internet y a las exigencias del soporte electrónico, y no ya en relación con el soporte papel. Así, los medios toman cierto protagonismo en el escenario normativo a partir de la producción de manuales de estilo para las ediciones on line de sus periódicos (cf. Arnoux, 2015a).

7. A continuación, mencionamos los nombres y la institución o el medio al que pertenecen -al momento de sus presentaciones- los expositores cuyos fragmentos de discursos son citados en este trabajo: Manuel Mourelle de Lema (profesor de la Universidad Complutense), Bartolomé Mitre (director del diario La Nación, Argentina), José Antonio Zarzalejos (director del diario $A B C$, España), Rafael Santos Calderón (director del periódico $E l$ tiempo, Colombia y Ecuador), Alejandro Fernández Pombo (presidente de la Federación Nacional de Asociaciones de la Prensa de España y exdirector del diario madrileño $Y a$ ), Álex Grijelmo (presidente de la Agencia de noticias EFE y exdirector general de Contenidos del Grupo Prisa), Enrique Durand (jefe de redacción de CNN en español), Jesús Ceberio Galardi (director del periódico El país, España), Carlos González Reigosa (director de publicaciones de la Agencia EFE), William Restrepo (director de servicios informativos de Radio Caracol, Miami), Alberto Gómez Font (responsable del Departamento del Español Urgente de la Agencia EFE y, desde 2005, coordinador de la Fundéu).

8. El diario La vanguardia tiene la particularidad de ser editado en Barcelona para toda España y publicado en español. A partir del año 2011 se sumó la edición en catalán.

9. Estos medios están incluidos en los agradecimientos del $D P D$ (cf. nota 4).

10. La Agencia EFE creó en el año 1980 un organismo destinado a promover el buen uso del español en los medios de comunicación mediante la unificación de criterios lingüísticos: el Departamento del Español Urgente (DEU). En el año 2005 el DEU se fusionó en la Fundéu (Fundación del Español Urgente).
11. La estrecha relación entre el Instituto Cervantes y la Fundéu ha sido definida en 2008 por la entonces directora de aquella entidad, Carmen Caffarel, como "casi una pareja de hecho" (Instituto Cervantes, 2008).

12. Cf. Academia Argentina de Letras (abril de 2012).

13. Cf. http://www.fundeu.es/sobre-fundeu/entidadescolaboradoras/convenios/ [consulta: 01-12-2016].

14. Cadena Radial Colombiana (Caracol) es un sistema de estaciones de radio que abarca todo el territorio nacional. Desde el año 2003/2004 es propiedad del Grupo Prisa.

15. El siguiente fragmento de una nota publicada en el año 2011 en el diario Clarín, a raíz de la polémica desatada por un intento de control por parte de la RAE de los contenidos de sus obras publicados en internet, exhibe la estrecha relación entre esta institución y el Grupo Planeta: "El periodista uruguayo Ricardo Soca recibió una intimación en su sitio www.elcastellano.org, que él mismo modera desde 1996. El departamento jurídico del Grupo Planeta, que edita buena parte de las publicaciones impresas de la RAE, entre ellos su Diccionario y Gramática, le solicitó -'en nombre de la RAE'que retirara inmediatamente del sitio los avances de la vigésima tercera edición del diccionario académico, que verá la luz en 2014. Soca supo, en una conversación telefónica con Alex Calvo, responsable jurídico de Planeta, que el suyo no fue el único sitio 'advertido'. 'UStedes tienen un poder de la Real Academia para actuar en su nombre?', preguntó Soca. 'Así es', le devolvieron” (Carelli Lynch, 2011).

16. Cf. http://www.eltiempo.com/archivo/documento/ CMS-11610965 [consulta: 01-12-2016].

17. Los textos citados en este trabajo fueron extraídos de las actas digitales de los CILE que pueden consultarse en http://www.congresosdelalengua.es [consulta: 01-12-2016]. Los destacados en cursiva nos pertenecen.

18. A grandes rasgos, podemos definir la noción de ideologías lingüisticas, acuñada por la Antropología Lingüística, como "representaciones, sean explícitas o implícitas, que interpretan la relación entre la lengua y los seres humanos en el mundo social" (Woolard, 2012: 19) y en las que, por lo tanto, intervienen las variadas negociaciones que 
producen, reproducen o luchan por el orden social. De acuerdo con la propuesta de J. Del Valle y E. Arnoux, "las ideologías lingüísticas se inscriben en regímenes de normatividad que, al actuar desde las instituciones, son generadores de discursividades legítimas" (2010: 6). Estos dispositivos pueden ser reconstruidos en distintas materialidades: prácticas discursivas, evaluaciones de los hablantes o textos reguladores como gramáticas (Arnoux y Del Valle, 2010: 6).

19. La identificación de un rasgo que presenta regularidad a lo largo de los CILE no implica que sea la única posición sostenida en este tipo de acontecimientos. En efecto, es posible identificar en otros discursos, aunque no de forma extendida, una ideología lingüística que valora el uso, donde prima este aspecto por sobre la corrección, en especial en exposiciones que abordan la cuestión del spanglish, tema que ha despertado numerosas polémicas en el ámbito académico universitario de los Estados Unidos y en los medios de comunicación, principalmente en los comienzos del siglo XXI (cf. Rizzo, 2014).

20. Sin embargo, el tratamiento de la RAE hacia la prensa no siempre va en la misma dirección. Por ejemplo, en la Nueva Gramática de la Lengua Española (2009) se percibe una relación ambivalente hacia los medios gráficos en la medida en que, de acuerdo con E. Arnoux (2015b), se reconoce, por un lado, el lenguaje periodístico como una de las manifestaciones del estándar español y, por ello, constituye una de las fuentes de datos de la Nueva Gramática pero, por el otro, es cuestionado en numerosas ocasiones.

21. Constituyen rasgos centrales de esta matriz la conformación y difusión de una variedad - "la" lengua española- que centralice las formas divergentes y que se erija en modelo al cual deben adaptarse las prácticas lingüísticas; la formación de una conciencia de pertenencia a un imaginario identitario - la comunidad hispánica- que sirva de sustento a lo anterior; y la asunción de un liderazgo "natural" por parte de España frente a los países hispanoamericanos. Abordamos la matriz discursiva de los congresos de la lengua en Rizzo (2016).

\section{Bibliografía}

Academia Argentina de Letras. Abril de 2012. Boletín informativo digital. Recuperado de http://www.aal.edu.ar/BID/bid19.pdf. Consulta: 01-12-2016.

Arnoux, Elvira Narvaja de. 2000. "La glotopolítica: transformaciones en un campo disciplinario". En: Revista Lenguajes: teorías y prácticas, 1: 3-27.

Arnoux, Elvira Narvaja de. 2008. "'La lengua es la patria', 'nuestra lengua es mestiza' y 'el español es americano': desplazamientos significativos en el III Congreso de la Lengua Española". En: Hofmann (ed.): 17-39.

Arnoux, Elvira Narvaja de. 2013. "En torno a la Nueva gramática de la lengua española". En: Arnoux y Nothstein (eds.): 245-270.

Arnoux, Elvira Narvaja de. 2014. "Glotopolítica: delimitación del campo y discusiones actuales con particular referencia a Sudamérica”. En: Zajícová y Zámec (eds.): 19-43.

Arnoux, Elvira Narvaja de. 2015a. "El español global y la regulación de la discursividad en línea como piezas del dispositivo glotopolítico español". En: Tavares de Sousa y Roca (orgs.): 35-68.

Arnoux, Elvira Narvaja de. 2015b. “El dispositivo normativo en la Nueva gramática básica de la lengua española". En: Arnoux y Bein (eds.): 243-268.

Arnoux, Elvira Narvaja de y Roberto Bein (comps.). 1999. Prácticas y representaciones del lenguaje. Buenos Aires: Eudeba.

Arnoux, Elvira Narvaja de y Roberto Bein (eds.). 2015. Políticas lingüísticas y enseñanza de lenguas. Buenos Aires: Biblos.

Arnoux, Elvira Narvaja de, María Imelda Blanco y Mariana Di Stefano. 1999. 
"Las representaciones de la lengua y de la prensa en los manuales de estilo periodísticos argentinos". En: Arnoux y Bein (comps.): 175-190.

Arnoux, Elvira Narvaja de y José Del Valle. 2010. "Las representaciones ideológicas del lenguaje. Discurso glotopolítico y panhispanismo". En: Spanish in Context 7(1): 1-24.

Arnoux, Elvira Narvaja de y Susana Nothstein (eds.). 2013. Temas de Glotopolitica: integración regional y panhispanismo. Buenos Aires: Biblos.

Blanco, María Isabel. 1993. "El léxico del purismo en la Argentina". En: Fontanella de Weinberg, Vallejos Llobet e Hipperdinger (eds.): 97-116.

Carelli Lynch, Guido. 6 de octubre de 2011. "La RAE quiso controlar el uso de sus contenidos y hay polémica". Clarín. Recuperado de http://www.clarin. com/sociedad/RAE-quiso-controlarcontenidos-polemica_0 567543344.html. Consulta: 11-10-2016.

Del Valle, José. 2014. "Lo político del lenguaje y los límites de la política lingüística panhispánica”. En: Boletín de Filología XLIX (2): 87-112.

Del Valle, José y Luis Gabriel-Stheeman. 2004. "Nacionalismo, hispanismo y cultura monoglósica". En: Del Valle y GabrielStheeman (eds.): 15-34.

Del Valle, José y Luis Gabriel-Stheeman (eds.). 2004. La batalla del idioma: la intelectualidad hispánica ante la lengua. Madrid/Krankfurt: Iberoamericana/ Vervuert.

Del Valle, José y Laura Villa. 2012. "La disputada autoridad de las academias: debate lingüístico-ideológico en torno a la Ortografía de 2010". En: Revista Internacional de Lingüística Iberoamericana X (10): 29-53.

Fanjul, Adrián Pablo. 2011. “«Policêntrico»e «pan-hispânico». Deslocamentos na vida política da língua espanhola”. En: Lagares y Bagno (orgs.): 299-331.

Fontanella de Weinberg, Beatriz, Patricia Vallejos Llobet y Yolanda Hipperdinger (eds.). 1993. Estudios sobre el español de la Argentina II. Bahía Blanca: Universidad Nacional del Sur.

Hofmann, Sabine (ed.). 2008. Más allá de la nación. Medios, espacios comunicativos y nuevas comunidades imaginadas. Berlín: Edition Tranvía.

Instituto Cervantes. 19 de junio de 2008. "Carmen Caffarel se incorpora al Patronato de la Fundéu". Recuperado de http://www. cervantes.es/sobre instituto cervantes/ prensa/2008/noticias/noticia 08-06-19a. htm. Consulta: 11-10-2016.

Lagares, Xoan y Marcos Bagno (orgs.) Políticas da norma e conflitos linguísticos. San Pablo: Parábola.

Lara, Luis Fernando. 2011. "El símbolo, el poder y la lengua”. En: Senz y Alberte (eds.). vol. I: $315-341$.

Marimón Llorca, Carmen. 2015. “Ideologías lingüísticas del español: la dimensión política del panhispanismo en los Congresos Internacionales de la Lengua Española". En: Circula. Revued'idéologies linguistiques, 1: 110-129.

Milroy, James y Leslie Milroy. 1985. Authority in Language: Investigating Standard English. London: Routledge. 
Moreno Cabrera, Juan Carlos. 2011. "Unifica, limpia y fija'. La RAE y los mitos del nacionalismo lingüístico español". En: Senz y Alberte (eds.). vol. I: 157-314.

Paffey, Darren. 2007. "Policing the Spanish language debate: verbal hygiene and the Spanish language academy (Real Academia Española)". En: Lang Policy, 6: $313-332$.

Paffey, Darren. 2012. "The role and authority of the Real Academia Española and other guardians of Spanish". En: Language ideologies and the globalization of "standard" Spanish. London/New York: Bloomsbury.

Real Academia Española y Asociación de Academias de la Lengua Española. 2004. La nueva política lingüística panhispánica. III Congreso Internacional de la Lengua Española. Rosario.

Real Academia Española y Asociación de Academias de la Lengua Española. 2005. Diccionario Panhispánico de Dudas. Bogotá: Santillana.

Reinoso, Susana. 15 de junio de 2001. “Triplicará los americanismos el diccionario de la Real Academia”. La Nación. Recuperado de http://www.lanacion.com. ar/312803-triplicara-los-americanismosel-diccionario-de-la-real-academia. Consulta: 11-10-2016.
Rizzo, María Florencia. 2013. “Antecedentes de la política lingüística panhispánica: los congresos de la lengua española". En: Arnoux y Nothstein (eds.): 191-220.

Rizzo, María Florencia. 2014. Los discursos de los Congresos Internacionales de la Lengua Española (1997-2007): perspectiva glotopolítica. Tesis doctoral. Facultad de Filosofía y Letras, Universidad de Buenos Aires.

Rizzo, María Florencia. 2016. "Los congresos de la lengua española: configuración de una matriz discursiva". En: Anclajes XX (3): 59-75.

Senz, Silvia. 2011. "Una, grande y esencialmente uniforme. La RAE en la conformación y expansión de la «lengua común»". En: Senz y Alberte (eds.). vol. II: 9-302.

Senz, Silvia y Montserrat Alberte (eds.). 2011. El dardo en la Academia. Esencia y vigencia de las academias de la lengua española, vols. I y II. Barcelona: Melusina.

Schieffelin, Bambi, Kathryn Woolard y Paul Kroskrity (eds.). 2012. Ideologías lingüisticas. Práctica y teoría. Madrid: Los libros de la Catarata.

Subirats Rüggeberg, Carlos. 2014. “¿Qué hace una lengua como el español en una academia como ésta? La institucionalización del atraso en la lingüística hispánica". En: Zimmermann (ed.): 105-127. 
Tavares de Sousa, Socorro y María del Pilar Roca (orgs.). 2015. Politicas linguísticas declaradas, praticadas e percebidas. João Pessoa: UFPB Editora.

Woolard, Kathryn. 2012. "Introducción". En: Schieffelin, Woolard y Kroskrity (eds.).
Zajícová, Lenka y Radim Zámec (eds.). Lengua y politica en América Latina: perspectivas actuales. Olomouc: Univerzita Palackého v Olomouci.

Zimmermann, Klaus (ed.). 2014. Prácticas y politicas lingüisticas. Nuevas variedades, normas, actitudes y perspectivas. Madrid: Iberoamericana/Vervuert.

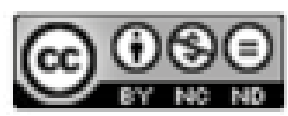

Este obra está bajo una licencia de Creative Commons Reconocimiento-NoComercial-SinObraDerivada 4.0 Internacional. 